\title{
Functional Outcomes and Hop Tests Results in Anterior Cruciate Ligament Reconstruction Patients with Adjustable Loop Fixation: 2-Years Follow-up
}

\author{
Sholahuddin Rhatomy ${ }^{1,2 *}$, Chairul Wahjudi ${ }^{3}$, Thomas Edison Prasetyo ${ }^{3}$, Riky Setyawan ${ }^{3}$, Nicolaas C. Budhiparama ${ }^{4}$ \\ ${ }^{1}$ Department of Orthopaedics and Traumatology, Dr. Soeradji Tirtonegoro General Hospital, Klaten, Indonesia; ${ }^{2}$ Faculty of \\ Medicine, Public Health, and Nursing, Universitas Gadjah Mada, Yogyakarta, Indonesia; ${ }^{3}$ Soeradji Tirtonegoro Sport Center and \\ Research Unit, Dr. Soeradji Tirtonegoro General Hospital, Klaten, Indonesia; ${ }^{4}$ Nicolaas Institute of Constructive Orthopaedics \\ Research and Education Foundation for Arthroplasty and Sports Medicine, Medistra Hospital, Jakarta, Indonesia
}

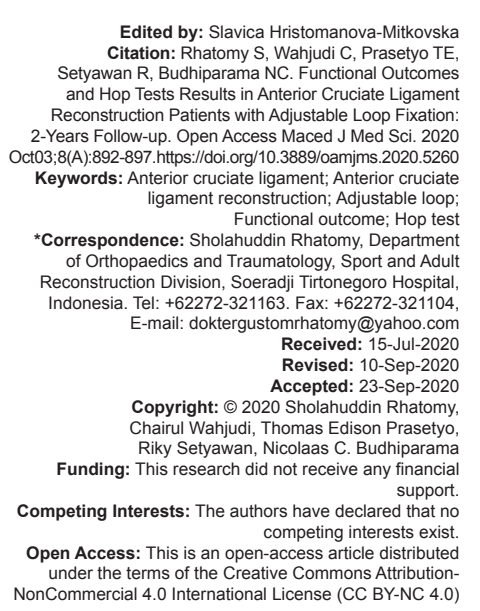

\section{Abstract}

BACKGROUND: Grafts are ultimately integrated into the bone tunnels by either screws, cross-pins, or cortical suspension devices in anterior cruciate ligament $(\mathrm{ACL})$ reconstruction. Investigation the usage of adjustable loop button is inadequate.

AIM: The aim of this study was to identify knee functional outcome and serial hop test in ACL reconstruction with adjustable loop button in 2-years follow-up.

METHODS: Chronic isolated ACL ruptured patients were reconstructed with adjustable loop button using peroneus longus autograft. We recorded knee functional outcome score using Tegner-Lysholm score, Modified Cincinnat score, and International Knee Documentation Committee (IKDC) at pre-operative and 2-years follow-up. Serial hop test was assessed at 6 months after surgery.

RESULTS: Forty-seven patients fulfilled inclusion criteria with median age 22.0. Evaluation of functional outcome of Tegner-Lysholm score, Modified Cincinnati score, and IKDC showed significant improvement at 2-years follow-up compared to pre-operative. Serial hop test showed excellent result at 6 months after surgery.

CONCLUSION: The result of knee functional score (Tegner-Lysholm score, Modified Cincinnati score, and IKDC) and serial hop test in ACL reconstruction with adjustable loop using peroneus longus autograft was excellent at 2-years follow-up.

LEVEL OF EVIDENCE: Level 2, Retrospective Cohort Study

\section{Introduction}

The most common knee surgery is anterior cruciate ligament (ACL) reconstruction. It produces early return to sport and good clinical outcomes [1], [2], [3], [4], [5], [6], [7]. The outcomes are affected by various factors, such as type of grafts, graft fixation methods, tunnel orientations, graft diameters, and rehabilitation program. The most common graft is Bone-Patellar Tendon-Bone (BPTB), hamstring tendon $(\mathrm{HT})$, and quadriceps tendon (QT) grafts [8]. These grafts are comparable both in their biomechanical properties and clinical outcomes, although different morbidities in their respective harvesting sites [4], [7], [9]. Other graft, such as peroneus longus tendon (PLT) graft, is being studied [10], [11], [12], [13].

Grafts are ultimately integrated into the bone tunnels by either screws, cross-pins, or cortical suspension devices. Cortical suspensory fixations have been demonstrated to possess superior biomechanical properties to both screws and cross-pins [14]. A fixedloop button was commonly used as cortical suspension device on the femoral side. Although they provide desirable biomechanical properties, it needs more drilling on femoral tunnel that may disturb graft integration and widen the tunnel size. Therefore, adjustable loop cortical suspensory devices have been designed for easier loop length calculation and integration of the grafts in the femoral tunnel. However, concerns have been raised regarding adjustable loop loosening due to cyclic loading in experimental studies. The loosening was not found in fixed loop devices, and potentially results in knee laxity postoperatively [15], [16].

There have been only seven publications that studies about ACL reconstruction clinical outcomes using adjustable loop devices. These studies consistently show that adjustable loop devices and other femoral fixation methods bear similar functional outcomes, as evaluated by the International Knee Documentation Committee (IKDC) score, Tegner-Lysholm score, and other criteria [16], [17], [18], [19], [20], [21]. Loop loosening 
did not significantly differ, neither in radiographs nor clinically [18], [19, [20]. However, Tunnel widening which was a drawback in fixed loop fixation was not decreased in adjustable loop fixation [17].

Hop tests were designed as one of the performance test for determining patients' readiness for return to sport after $\mathrm{ACL}$ reconstruction. There indeed has been much debate in return to sport criteria, but hop tests have been the most widely studied performance test because of its simplicity and reproducibility [22], [23], [24].

The purpose of this study was to evaluate the functional outcomes and hop tests in patients with post-operative ACL reconstruction with adjustable loop button fixation for femoral site fixation after 2-years of follow-up. The post-operative functional outcomes would be compared to the preoperative. This study hypothesized that there would be a significant increase of functional outcomes.

\section{Methods}

We conducted a single-centered retrospective study in patients diagnosed with ACL rupture from January to July 2017. All patients that included in this study, completed informed consent forms, and underwent $A C L$ reconstruction surgery with adjustable loop button fixation and PLT as the graft.

ACL rupture diagnosis was established by history taking, physical examination, and MRI examination. The inclusion criteria were patients with chronic ACL total rupture without any additional ligament injury around knee joint. Exclusion criteria, there should be any history of lower limb fracture, multiple ligament injury, and concomitant with meniscus rupture. All patients who met the inclusion and exclusion criteria will be contacted, in which they would receive informed consent forms within the duration of sample collection. Theoretically, minimum sample needed could be calculated as follows:

$$
\mathrm{N}=\frac{\left(Z_{\alpha}+Z_{\beta}\right)^{2}}{(\mathrm{E} / \mathrm{SD})^{2}}
$$

$\mathrm{N}=$ minimum sample size

$Z^{\alpha}=$ normal standard deviation for $\alpha$

$Z^{\beta}=$ normal standard deviation for $\beta$

$E=$ size effect

$\mathrm{SD}=$ standard deviation in results

By choosing $\alpha=0.05, \beta=0.20, E=0.60$ and $\mathrm{SD}=1.00$, the value of $N$ will be 21.80 . Thus, the minimum sample size needed in this study is 22 .
The functional outcomes were reported as preoperative and 2-years post-operative Tegner-Lysholm score, Modified Cincinnati score, and IKDC. The results of the 6 months post-operative hop tests would also be recorded. This study was approved by Medical Ethics Committee with IRB number KE/FK/0148/EC/2019.

\section{Surgical procedure}

All of ACL reconstruction surgery was done by single orthopedic surgeon. SR did all of the procedure. In ipsilateral leg, surgeon used an open tendon stripper to harvest peroneus longus tendon. Through anteromedial portal, femoral drill guide was inserted. Femoral drill guide was placed at $A C L$ foot print on the medial wall of lateral femoral condyle. Guide pin was ensured in accurate intra-articular position. Surgeon was created a full-length $6 \mathrm{~mm}$ wide femoral tunnel using outside-in approach. ACL tibial drill guide was inserted through anteromedial portal to create the tibial tunnel. Tibial drill guide was placed at the center of the ACL tibial stump. A 6-mm tibial tunnel was created under direct visualization using a low-speed drilling method. Number 2 Vicryl suture was used to calculate the ACL length from proximal femoral tunnel to distal tibial tunnel. The harvested peroneus longus tendon was marked according to the ACL length measurement.

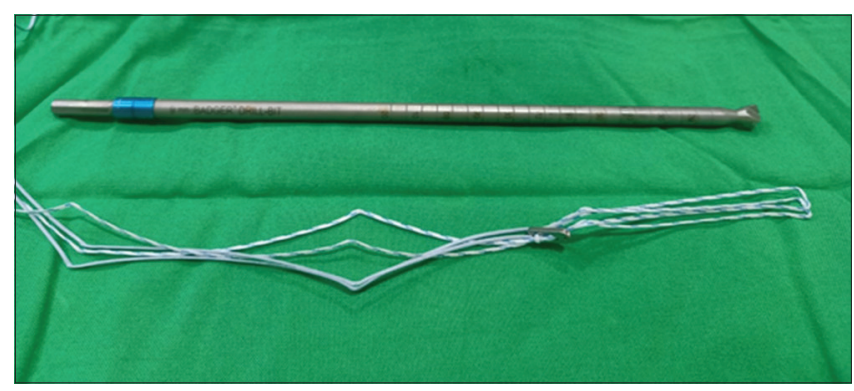

Figure 1: Adjustable-loop suspensory fixation device

Femoral stabilization was fixed using an adjustable-loop suspensory fixation (ALSF) device (GraftMax ${ }^{\mathrm{TM}}$ Button, Conmed, USA [Figures 1 and 2]). The suture guide was pulled until all the graft suture had passed the femoral skin. The graft was fastened with bioabsorbable screw at tibial site with $90^{\circ}$ knee flexion and posterior drawer of the tibia. There were no additional securing knots over the ALSF. The remaining graft was sutured with fascia. Surgeon closed and the operation were done. Rehabilitation program

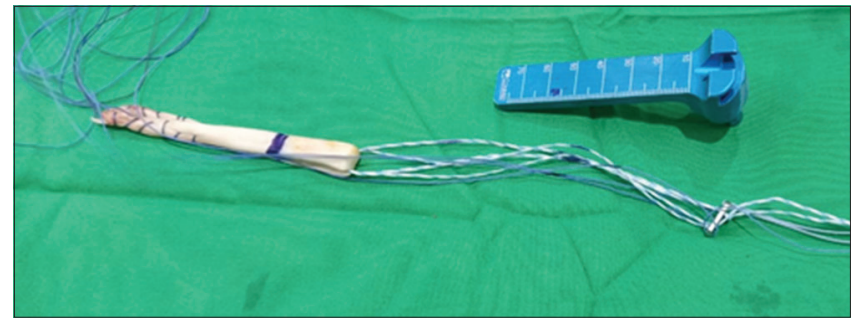

Figure 2: Hamstring graft with adjustable-Loop Suspensory Fixation device 
After surgery was finished, patients were passed the ACL rehabilitation program. The operated knee was positioned in extension position soon after surgery. Knee flexion was exercised progressively until 3-weeks post-operative to achieve $90^{\circ}$ flexion position. Patients were allowed to mobilize with partial weight bearing for first 3-weeks post-operative. Full weight bearing was allowed to patients after 3-weeks post-operative. At 2 months after surgery, the patients were allowed to jog. Patients were tested the Lachmann test, anterior drawer test, serial hop test, and knee functional outcome at 6 months follow-up. After patients passed the test, they were allowed to return to sport activity.

\section{Patient outcomes}

Patients were interviewed and examined 2 years after the ACL reconstruction for the functional outcomes by an experienced sports clinician who did not participate in the surgery. The assessment was done using IKDC, Cincinnati, and Tegner-Lysholm score which were adjusted to a scale of 100 . Hop tests were evaluated on 6 month after the surgery.

\section{Statistical analysis}

Statistical Package for the Social Sciences (SPSS) program version 25.0 (IBM Corporation, USA) was utilized to calculate for the statistical analysis. For each scores of the functional outcomes, the results were expressed in means and standard deviations. The normality data distribution was evaluated using Kolmogorov-Smirnov test. If the data were normally distributed, paired t-test would be used to determine significant differences between the functional outcomes before and after surgery. If not, a Wilcoxon signed-rank test would be used instead. Hop tests data distribution checked using Kolmogorov-Smirnov test. Statistical significance was obtained, if $p<0.05$.

\section{Results}

In total, there were 47 patients enrolled in this study. The baseline information of the patients is presented in Table 1. Median value of the age was 22 years, with 40 male subjects $(85.1 \%)$ and seven female subjects (14.9\%). The identifiable cause of ACL rupture was related to sports $38(80.9 \%)$ subjects, such as basketball, volleyball, and football, or accidents 9 (19.1\%) subjects. Median Body Mass Index (BMI) was found to be 25.0 .
Table 1: Subject characteristics

\begin{tabular}{lll}
\hline Characteristics & Median (percentile 25 - percentile 75$)$ & $\mathrm{n}(\%)$ \\
\hline Age & $22(20-33)$ & \\
Sex & & $7(14.9)$ \\
Female & & $40(85.1)$ \\
Male & $25(23-26)$ & \\
BMI & & $38(80.9)$ \\
Cause of ACL Rupture & & $9(19.1)$ \\
$\quad$ Sports related & \\
Accident & & \multicolumn{2}{c}{ Kolmogorov-Smirnov test was done to all }
\end{tabular}

functional outcome parameters to check for their distribution normality, and it is found that only IKDC pretest data have a normal distribution ( $p=0.200$ ). Therefore, Wilcoxon Signed-Rank test was used to assess significant differences between pre-operative and 2-years post-operative IKDC score, TegnerLysholm score, and Cincinnati score.

Table 2: Functional outcomes

\begin{tabular}{lll}
\hline Variables & Median (percentile 25-percentile 75) & p value \\
\hline IKDC & $56.3(46.0-65.0)$ & $<0.001$ \\
$\quad$ Pre-operative & $95.6(92.0-97.7)$ & \\
$\quad$ Post-operative & $73.0(63.0-78.3)$ & $<0.001$ \\
Tegner-Lysholm & $98.0(96.0-99.0)$ & \\
$\quad$ Pre-operative & $70.5(53.8-77.0)$ & $<0.001$ \\
$\quad$ Post-operative & $95.0(93.0-99.0)$ & \\
Cincinnati & Pre-operative & \\
Post-operative &
\end{tabular}

Results of pre-operative and 2-years postoperative functional outcomes are shown in Table 2. The IKDC score, Tegner-Lysholm score, and Cincinnati score yielded statistically significant differences $(p<0.001)$ between their pre- and post-operative score. The median of the hop tests was 92, 94, 94, and 95 for the single, triple, cross over, and timed tests, respectively, as shown in Table 3.

Table 3: Hop test

\begin{tabular}{ll}
\hline Type & Median (percentile 25-percentile 75) \\
\hline Single hop & $92(90-94)$ \\
Triple hop & $94(92-96)$ \\
Cross over hop & $94(94-96)$ \\
Timed hop & $95(88-98)$ \\
\hline
\end{tabular}

\section{Discussion}

In the present study, we found that all functional outcomes are significantly different between pre-operative and post-operative subjects. In addition, the median postoperative Tegner-Lysholm, IKDC, and Cincinnati scores were more than 95.0. The TegnerLysholm score median was 98.0, which was higher than the excellent cutoff (>90 according to Mitsou et al.) and the Cincinnati score median was 95.0, which was also higher than the excellent cutoff (>80 according to Bentley et al.) [25], [26]. On the other hand, IKDC score is a subjective scoring system that might be affected by gender and factors; hence, it is more difficult to make the cutoffs [27]. However, we believed that median score of 95.6 could be inferred as an excellent score as well. 
These findings indicated that ACL reconstruction using adjustable loop device and PLT would have favorable functional outcomes.

Adjustable loop fixation method was introduced in 2012. There are lot of ongoing researches regarding its utilization. However, these studies mainly focused on common used autografts such as BPTB, HT, and QT grafts. Study of PLT graft and an adjustable loop fixation usage concurrently was conducted by Khajotia et al. [28]. In their study, they included 25 patients and used ALSF device by TightRope RT (Arthrex) for the femoral site fixation. Their method of PLT graft harvesting and ACL reconstruction was similar to us. Functional outcomes were assessed using IKDC score in 6 months follow-up and the mean result was 83.53. Our study resulted in better IKDC score at 95.6 in longer period of follow-up. The longer follow-up period could be explained by stronger integration of the grafts in the femoral tunnel. Ranjan et al. stated that the IKDC score was higher in 2 years rather than 6 months of follow-up [21]. There was no function deterioration of the ankle joint when compared to the normal ankle [28]. However, these might be attributable to the small sample size used in these studies [28].

There are few studies that assessed the clinical outcomes of the adjustable loop fixation. Boutsaidis et al. studied a total of 272 patients who had undergone $A C L$ reconstruction with either adjustable loop fixation (Pullup XL, SBM) or bioabsorbable screw fixation with approximately 2 year of follow-up [20]. Post-operative IKDC score was significantly higher in adjustable loop group compared to the screw group. Although the average IKDC score was not stated, 81.6\% of the subjects was Graded A (normal) postoperatively. It concluded that the operation yielded favorable results.

Ranjan et al. compared 2 types of suspensory fixations, the adjustable loop (TightRope RT, Arthrex) and fixed loop (Endobutton CL Ultra, Smith and Nephew) in 102 patients [21]. The study concluded that the functional outcomes of both suspensory fixations using IKDC and Tegner-Lysholm scores showed no significant different in 2-years follow-up. Average IKDC scores for the adjustable and fixed loop were 84.3 and 85.2, respectively. Our study resulted in higher post-operative average IKDC score 95.6. This difference might be caused by different type of graft. We used PLT autograft while Ranjan et al. used HT autograft. The previous studies comparing PLT and other more common used autograft resulted in similar functional outcomes [10], [12], [13]. Thus, other factors might have contributed to this difference such as interobserver errors in evaluating functional outcomes and small sampling size. Sundararajan et al. observed a relatively low average 78.4 in IKDC score and 87.25 in Tegner-Lysholm score after 2-years follow-up of ACL reconstruction in patients with adjustable loop fixation (TightRope RT, Arthrex) [17]. Study by Ranjan et al. showed that the functional outcomes of adjustable loop and fixed loop (Endobutton CL Ultra, Smith and Nephew) groups were not significant different.
Hop tests are easily performed and widely used tool for assessing patients' readiness to return to sport including psychological readiness. Patients were performed four common forms of hop tests: The single one-leg, triple one-leg, crossover one-leg, and 6-m timed hop test at 6 months after ACL reconstruction. Systematic review by Hegedus et al. concluded that physical performance tests, including hop tests, should be used with caution [22]. Return to sport criteria decision was developed; include other performancebased test and patient-reported measurement of knee function. These criteria are still lack of consensus [29], [30]. Nawasreh et al. found that at 12 and 24 months follow-up, hop test as outcome predictor was consistent [29]. The 6-m hop test combined with single hop test was indicated a half of the outcome variation at 24 months after ACL reconstruction. Based on good hop tests result, our study might be predicted to have higher subjects for returning to sport.

This study has several limitations. This study did not compare the method of fixation using adjustable loop fixation to other methods such as fixed-loop, and screw. This study had few subjects. Greater number of subjects will provide a more reliable result. This study did not include return to sport analysis, although we included the hop tests results.

\section{Conclusion}

ACL reconstruction with adjustable loop fixation (GraftMax ${ }^{\mathrm{TM}}$ Button, CONMED) on the femoral site had excellent functional outcomes in 2-years of follow-up with excellent serial hop test.

\section{Acknowledgments}

We thank to Rini Maya Puspita, MD for the journal reference suggestion.

\section{References}

1. Abrams GD, Forsythe B, Williams D, Verma NN, Harris JD, Bush-Joseph CA, et al. Return to sport after ACL reconstruction. Orthopedics. 2014;37(2):e103-8. https://doi. org/10.3928/01477447-20140124-10

PMid:24679194

2. Lai CC, Ardern CL, Feller JA, Webster KE. Eighty-three per cent of elite athletes return to preinjury sport after anterior cruciate ligament reconstruction: A systematic review with meta-analysis of return to sport rates, graft rupture rates and performance outcomes. Br J Sports Med. 2018;52(2):128-38. https://doi. 
org/10.1136/bjsports-2016-096836

PMid:28223305

3. Kay J, Memon M, Marx RG, Peterson D, Simunovic N Ayeni OR. Over $90 \%$ of children and adolescents return to sport after anterior cruciate ligament reconstruction: A systematic review and meta-analysis. Knee Surg Sports Traumatol Arthrosc. 2018;26(4):1019-36. https://doi.org/10.1007/ s00167-018-4830-9

PMid:29332225

4. Tan SH, Huh L, Krishna L. Outcomes of anterior cruciate ligament reconstruction in females using patellar-tendonbone versus hamstring autografts: A systematic review and meta-analysis. J Knee Surg. 2019;32(8):770-87. https://doi. org/10.1055/s-0038-1669916

PMid:30212919

5. Ross KE, Ciccotti MG, Poehling-Monaghan KL, Freedman KB, Secrist $E$, Salem $H$, et al. Long-term outcomes in anterior cruciate ligament reconstruction: A systematic review of patellar tendon versus hamstring autografts. Orthop J Sport Med. 2017;5(6):1-9. https://doi.org/10.1177/2325967117709735 PMid:28660230

6. Saltzman BM, Mall NA, Cole BJ, Bach BR, Frank RM. Results after anterior cruciate ligament reconstruction in patients older than 40 years: How do they compare with younger patients? A systematic review and comparison with younger populations. Sports Health. 2016;8(2):177-81. https://doi. org/10.1177/1941738115622138

PMid:26674619

7. Chee MY, Chen Y, Pearce CJ, Murphy DP, Krishna L, Hui JH, et al. Outcome of patellar tendon versus 4-strand hamstring tendon autografts for anterior cruciate ligament reconstruction: $A$ systematic review and meta-analysis of prospective randomized trials. Arthroscopy. 2017;33(2):450-63. https://doi.org/10.1016/j. arthro.2016.09.020

PMid:28040335

8. Mosca M, Bait C, Carulli C, Grassi A, Innocenti M, Zaffagnini S. New trends in anterior cruciate ligament reconstruction: A systematic review of national surveys of the last 5 years. Joints. 2018;6(3):177-87. https://doi.org/10.1055/s-0038-1672157

PMid:30582107

9. Hardy A, Casabianca L, Andrieu K, Baverel L, Noailles T. Complications following harvesting of patellar tendon or hamstring tendon grafts for anterior cruciate ligament reconstruction: Systematic review of literature. Orthop Traumatol Surg Res. 2017;103(8):S245-8. https://doi.org/10.1016/j. otsr.2017.09.002 PMid:28888527

10. Rhatomy S, Asikin Al, Wardani AE, Rukmoyo T, LumbanGaol I, Budhiparama NC. Peroneus longus autograft can be recommended as a superior graft to hamstring tendon in single-bundle ACL reconstruction. Knee Surg Sports Traumatol Arthrosc. 2019;27(11):3552-9. https://doi.org/10.1007/ s00167-019-05455-w

PMid:30877316

11. Kerimoğlu S, Aynaci $O$, Saracoğlu M, Aydin H, Turhan AU, Anterior cruciate ligament reconstruction with the peroneus longus tendon. Acta Orthop Traumatol Turc. 2008;42(1):38-43. https://doi.org/10.3944/aott.2008.42.1.038 PMid:18354276

12. Shi FD, Hess DE, Zuo JZ, Liu SJ, Wang XC, Zhang $Y$, et al. Peroneus longus tendon autograft is a safe and effective alternative for anterior cruciate ligament reconstruction. J Knee Surg. 2018;32(8):804-11. https://doi. org/10.1055/s-0038-1669951

PMid:30206913
13. Bi M, Zhao C, Zhang S, Yao B, Hong Z, Bi Q. All-inside singlebundle reconstruction of the anterior cruciate ligament with the anterior half of the peroneus longus tendon compared to the semitendinosus tendon: A two-year follow-up study. J Knee Surg. 2018;31(10):1022-30. https://doi.org/10.1055/s-0038-1627466 PMid:29421837

14. Brand J, Weiler A, Caborn DN, Brown CH, Johnson DL. Graft fixation in cruciate ligament reconstruction. Am J Sports Med. 2000;28(5):761-74. https://doi.org/10.1177/0363546500028005 2501

PMid:11032238

15. Mae T, Shino K, Nakata K, Yoshikawa H, Nakagawa S, Tachibana $\mathrm{Y}$, et al. Mechanical properties of an adjustable-loop cortical suspension device for anterior cruciate ligament reconstruction. Orthop J Sport Med. 2018;6(8):1-4. https://doi.org/10.1177/2325967118791183 PMid:30151403

16. Choi NH, Yang BS, Victoroff BN. Clinical and radiological outcomes after hamstring anterior cruciate ligament reconstructions: Comparison between fixed-loop and adjustable-loop cortical suspension devices. Am J Sports Med. 2017;45(4):826-31. https://doi.org/10.1177/0363546516674183 PMid:27881383

17. Sambandam B, Sundararajan $S R$, Rajagopalakrishnan $R$, Singh A, Rajasekaran S. Does second-generation suspensory implant negate tunnel widening of first-generation implant following anterior cruciate ligament reconstruction? Knee Surg Relat Res. 2018;30(4):341-7. https://doi.org/10.5792/ ksrr.18.005

PMid:30466254

18. Kusano M, Kazui A, Uchida R, Mae T, Tsuda T, Toritsuka Y. Loop length change of an adjustable-length femoral cortical suspension device in anatomic rectangular tunnel anterior cruciate ligament reconstruction with a bone-patellar tendon-bone graft and associated clinical outcomes. Arthroscopy. 2018;34(11):306370. https://doi.org/10.1016/j.arthro.2018.06.034

PMid:30301633

19. Boyle MJ, Vovos TJ, Walker CG, Stabile KJ, Roth JM, Garrett WE. Does adjustable-loop femoral cortical suspension loosen after anterior cruciate ligament reconstruction? A retrospective comparative study. Knee. 2015;22(4):304-8. https://doi.org/10.1016/j.knee.2015.04.016

PMid:25999126

20. Boutsiadis A, Panisset JC, Devitt BM, Mauris F, Barthelemy R, Barth J. Anterior laxity at 2 years after anterior cruciate ligament reconstruction is comparable when using adjustableloop suspensory fixation and interference screw fixation. Am J Sports Med. 2018;46(10):2366-75. https://doi. org/10.1177/0363546518784005 PMid:30015501

21. Asif N, Kalra M, Ranjan R, Kumar R, Kumar A, Goel L, et al In vivo comparison of a fixed loop (EndoButton $\mathrm{CL}$ ) with an adjustable loop (TightRope RT) device for femoral fixation of the graft in ACL reconstruction: A prospective randomized study and a literature review. J Orthop Surg (Hong Kong). 2018;26(3):1-6. https://doi.org/10.1177/2309499018799787 PMid:30235984

22. Hegedus EJ, McDonough S, Bleakley C, Cook CE, Baxter GD. Clinician-friendly lower extremity physical performance measures in athletes: A systematic review of measurement properties and correlation with injury, Part 1. The tests for knee function including the hop tests. Br J Sports Med. 2015;49(10):642-8. https://doi.org/10.1136/bjsports-2014-094094 PMid:25497489

23. Davies GJ, McCarty E, Provencher M, Manske RC. ACL return to sport guidelines and criteria. Curr Rev Musculoskelet Med. 
2017;10(3):307-14. https://doi.org/10.1007/s12178-017-9420-9 PMid:28702921

24. Verma NN, Abrams GD, Gupta AK, McCormick FM, Cole BJ, Bush-Joseph CA, et al. Functional performance testing after anterior cruciate ligament reconstruction. Orthop J Sports Med. 2014;2(1):1-10. https://doi.org/10.1177/2325967113518305 PMid:2653526

25. MitsouA, Vallianatos P, Piskopakis N, Maheras S. Anterior cruciate over-the-top popliteus ligament repair tendon reconstruction combined with. J Bone Joint Surg Br. 1990;72(3):398-404. https://doi.org/10.1302/0301-620x.72b3.2341436

PMid:2341436

26. Bentley G, Biant L, Carrington R, Akmal M, GoldbergA, WilliamsA, et al. A prospective, randomised comparison of autologous chondrocyte implantation versus mosaicplasty for osteochondral defects in the knee. J Bone Joint Surg Br. 2003;85(2):223-30. https://doi.org/10.1302/0301-620x.85b2.13543

PMid: 12678357

27. Anderson AF, Irrgang JJ, Kocher MS, Mann BJ, Harrast JJ. The international knee documentation committee subjective knee evaluation form: Normative data. Am J Sports Med.
2006;34(1):128-35. https://doi.org/10.1177/0363546505280214 PMid:16219941

28. Khajotia BL, Chauhan S, Sethia R, Chopra BL. Functiona outcome of arthroscopic reconstruction of anterior cruciate ligament tear using peroneus longus tendon autograft. Int $\mathrm{J}$ Res Orthop. 2018;4(6):898-903. https://doi.org/10.18203/issn.24554510.intjresorthop20184382

29. Nawasreh Z, Logerstedt D, Cummer K, Axe M, Risberg MA, Snyder-Mackler L. Functional performance 6 months after $\mathrm{ACL}$ reconstruction can predict return to participation in the same preinjury activity level 12 and 24 months after surgery. Br J Sports Med. 2018;52(6):375. https://doi.org/10.1136/ bjsports-2016-097095

PMid:28954801

30. Rambaud AJ, Semay B, Samozino P, Morin JB, Testa R, Philippot R, et al. Criteria for return to sport after anterior cruciate ligament reconstruction with lower reinjury risk (CR'STAL study): Protocol for a prospective observational study in France. BMJ Open. 2017;7(6):e015087. https://doi.org/10.1136/ bmjopen-2016-015087

PMid:28667211 